\title{
CRÓNICA EPIGRÁFICA DEL SUDOESTE
}

José A. Correa

CORREA, JosÉ A.: “Grafito paleohispánico hallado en el depósito de Garvão (Ourique, Beja)”, Spal, 5, 1996, 167-170.

Grafito de seis signos (sólo cuatro diferentes) grabado en el pie de una taza (s. IV ${ }^{2}$-III), que el autor considera que pertenece a la escritura del SO. o "tartesia" con una variante desconocida para i y uso de la redundancia vocálica. Lectura: aiotiii. Se trata de un antropónimo formado sobre una base *aio-, bien documentada en la Península. Este grafito documenta la pervivencia de la citada escritura en la segunda Edad del Hierro.

VARElA GOMES, MÁRIO: Estela epigrafada e necrópole de Barradas, Benafim, Loulé, Loulé 1997, 16 págs.

Tirada aparte de un artículo aparecido en la revista al-'ulyã en el que se publica una inscripción en escritura del SO. que apareció por las mismas fechas como inédita en los $M L H I V$ con la sigla J.5.1. Su autor es un arqueólogo muy familiarizado con las estelas del SO. y en su trabajo hay que distinguir entre la lectura de la inscripción y su interpretación.

Se trata de una estela con el borde superior con perfil triangular y en cuyo tercio superior han sido escritas cuatro líneas con cartela, sensiblemente paralelas al borde superior izquierdo. Las tres líneas superiores forman un solo texto en disposición bustrofédica con inicio sinistrorso; la cuarta línea, algo distanciada, forma otro texto, de orientación sinistrorsa. La superficie está muy erosionada, sobre todo en su parte superior derecha, lo que dificulta la lectura. Para que el lector se haga una idea de las divergencias entre la lectura de Gomes y la de Untermann, transcribo ambas, si bien para que haya homogeneidad, dado que Gomes ofrece un dibujo (y fotografía) pero no una transcripción propiamente dicha, hago yo mismo la transcripción, probablemente no acertada en todos sus detalles, a partir del dibujo siguiendo los criterios de $M L H$ y no los de Gomes. Asimismo añado la lectura que, sin explicación, dan A. Marques de Faria y A. M. Monge Soares (artículo reseñado infra, p. 156), con una ligera adaptación tipográfica al uso de $M L H$. 
MLH

saboi : is* $^{*}$

ib $^{0}$ orinoeb $^{0}$ o

$\operatorname{anak}^{\mathrm{e} e n a k^{\mathrm{e}}}$ : e

ib $^{0}$ oiiba ${ }^{a}{ }^{a} b^{\text {a }}$ areii
GOMES

${ }^{*} \operatorname{oab}^{0} \mathbf{t}^{\mathrm{a}} \mathbf{i}$ : io

iborin : $\mathrm{e}^{*}$

*: *k $k^{\mathrm{e} e n a i k^{\mathrm{e}}}: \mathrm{e}$

$t^{\mathrm{e}} \mathbf{b}^{\mathbf{0}}$ oiib $^{\mathrm{a} i}$ are $\mathbf{b}^{\mathbf{0} *}$ ur
FARIA-MONGE

]oap ${ }^{0}$ oi [

liporii[

Japarenaŕ : $\mathrm{t}^{\mathrm{i}} \mathrm{i}$ [

Jpoiit ${ }^{\mathrm{e} e r n a r k}$ inir

No es posible tomar partido en lo divergente con sólo las fotografías publicadas, ya que, aunque he visto la inscripción en el museo de Loulé, no he podido examinarla. En cuanto a la transcripción que Gomes da de algunos segmentos, esta se basa en su convencimiento de que este sistema gráfico fue importado ya constituido y muestra afinidades con las escrituras arcaicas de Asia Menor (caria, frigia, etc.), griegas arcaicas (eolia y jonia) y etrusca, apareciendo diferenciado del fenicio; en consecuencia los valores fonéticos de los signos han de ser los que aparecen en esas escrituras. Hay que entender, en consecuencia, que también la lengua fue importada y debe tratarse de alguna de las que emplearon las escrituras citadas o estar emparentada con ellas, perdurando escritura y lengua lo que el pueblo que las usaba (ss. VIII-VI a. C.).

Este razonamiento a mi modo de ver tiene al menos dos fallos fundamentales. El primero es que confunde lengua con escritura, lo que lleva a no distinguir tampoco entre origen último de un sistema gráfico, que podría no ser exactamente la escritura fenicia, y su funcionamiento para una lengua dada. El segundo es que prescinde del resto de la escritura paleohispánica, siendo así que en el SE. de la península ibérica se usa casi el mismo catálogo de signos aunque con una norma ortográfica diferente. En fin, por muy chocante que sea la redundancia vocálica, su realidad es incontrovertible en el SO. y hay que contar con ella en cualquier intento de desciframiento. En todo caso lo único convincente sería una argumentación signo a signo basada en la comparación con los sistemas gráficos referidos y atendiendo a la estructura interna del sistema del SO. tal como se conoce en la actualidad.

Marques de Faria, António, Monge SoARes, António M.: "Uma inscrição em caracteres do Sudoeste proveniente da Folha do Ranjão (Baleizão, Beja)", Revista Portuguesa de Arqueologia 1,1, 1998, 153-160.

Pequeño fragmento de una placa muy delgada, que por esta razón no debió ser parte de una estela. Apareció en un lugar de abundantes restos cerámicos (campaniforme, bruñida, etc.), lo que permite atribuirla prudentemente a la primera Edad del Hierro; asimismo la situación geográfica le da una posición de enlace entre la epigrafía del Bajo Alentejo y la extremeña. Para la reproducción de la transcripción sigo de nuevo el uso tipográfico de $M L H$.

Cara A: ]eku u[. Cara B (con cartela inferior al menos): ]ir[. En esta cara hay además el resto de un ángulo de la cartela, que debió corresponder al final. 
Guerra, Amílcar, Ramos, Ana Cristina, Melro, SAmuel, PIRES, ISABEl AlEXANDRA: "Uma estela epigrafada da Idade do Ferro, proveniente do Monte Novo do Castelinho (Almodôvar)", Revista Portuguesa de Arqueologia, 2,1, 1999, 143-152.

Estela fragmentada de grandes dimensiones $(154 \times 64 \mathrm{~cm}$.) hallada reutilizada en una necrópolis romana tardía y que, por el desgaste que presenta en dos lugares de su única línea, ha debido tener una utilización previa en un lugar de paso. Sinistrorsa, con parte de la cartela superior conservada, presenta la singularidad de usar dos puntos como separador. Lectura: ] $\mathbf{k}^{\mathbf{0}}$ oloion : $\mathbf{k}^{\mathbf{0}} \mathbf{0 l o a r}[] \mathbf{r}[.] \mathbf{s}[] \mathbf{n t} \mathbf{t}^{\mathrm{i}}$.

Tras $\overline{\mathbf{k}^{\mathbf{0}}} \mathbf{0 l o a r}$ se advierten en la parte superior los ápices de dos letras. Entre ŕ y s se ve en la fotografía un asta vertical y un vacío, por lo que atendiendo al contexto se trataría de $\mathbf{i}$; parece menos probable que el asta funcione como separador. Aunque los autores no lo consideran probable, los dos trazos superiores que aparecen inmediatamente antes de $\mathbf{n t}^{\mathbf{i}} \mathbf{i}$ pueden corresponder a $\mathbf{k}^{\mathbf{e}}$, si bien en principio no parece quedar espacio para que siga e; téngase en cuenta sin embargo que este signo, un círculo, puede tener dimensiones muy reducidas y podría ir dentro del campo epigráfico propio de $\mathbf{k}^{\mathbf{e}}$. En ese caso se trataría de uno de los finales conocidos de la fórmula, $\mathbf{k}^{\mathbf{e}} \mathbf{e n t} \mathbf{t}_{\mathbf{i}}$, quedando espacio para que le precediera, como de costumbre, naŕ y algo más después de $\mathbf{s}$.

La seguridad de segmentación que ofrecen los inusitados dos puntos, señalada por los autores, creo que invita a pensar que en el texto conservado tal vez esté el nombre del difunto (con un final -ion bien documentado) seguido del patronímico, dada la identidad del segmento $\mathbf{k}^{\mathbf{0}} \mathbf{0 l o}$ - . En este supuesto es probable que no faltara nada al comienzo de la inscripción.

José A. Correa Rodríguez

Universidad de Sevilla e-mail: jcorrea@siff.us.es 